\title{
Severe aortic regurgitation in a patient with left ventricular non-compaction cardiomyopathy
}

\author{
¿Zrinka Planinić1 ${ }^{*}$, \\ (1) Petra Grubić \\ Rotkvić', \\ (10)Jasna Čerkez \\ Habek ${ }^{1,2}$, \\ 이라k Perčić', \\ (1) Petar Bešlić', \\ - Edvard Galić1,3, \\ (1) Jozica Šikić ${ }^{1,3}$
}

'University Hospital "Sveti Duh", Zagreb, Croatia

${ }^{2}$ Croatian Catholic University, Zagreb, Croatia

${ }^{3}$ University of Zagreb, School of Medicine, Zagreb, Croatia

\begin{abstract}
KEYWORDS: non-compaction cardiomyopathy, aortic regurgitation, heart failure. CITATION: Cardiol Croat. 2021;16(9-10):290. | https://doi.org/10.15836/ccar2021.290
\end{abstract}

*ADDRESS FOR CORRESPONDENCE: Zrinka Planinić, Klinička bolnica „Sveti Duh“, Sv. Duh 64, HR-10000 Zagreb, Croatia. / Phone: +385-91-3714-308 / E-mail: zrinkaplaninic@gmail.com

ORCID: Zrinka Planinić, https://orcid.org/0000-0001-8664-3338 • Petra Grubić Rotkvić, https://orcid.org/0000-0002-2587-1932 Jasna Čerkez Habek, https://orcid.org/0000-0003-3177-3797 • Marko Perčić, https://orcid.org/0000-0001-7904-8899 Petar Bešlić, https://orcid.org/0000-0001-6141-6526• Edvard Galić, https://orcid.org/0000-0002-5707-0961 Jozica Šikić, https://orcid.org/0000-0003-4488-0559

\section{|||||||||||||||||||||||||||||||||||||||||||||||||||||||||||||||||||||||||||||||||||||||||||||||||||||||}

Introduction: Left ventricular non-compaction (LVNC) is a rare congenital cardiomyopathy characterized by excessive trabeculation and deep intertrabecular recesses most commonly affecting apical and mid-ventricular inferior and lateral segments. These patients are more prone to develop a typical triad of heart failure, thromboembolic events, and malignant arrhythmias. LVNC often coexists with other congenital or valvular heart diseases. Echocardiography is the standard imaging for the diagnosis of LVNC with several proposed criteria, mainly based on the ratio of non-compacted to compacted myocardial thickness ${ }^{1,2}$

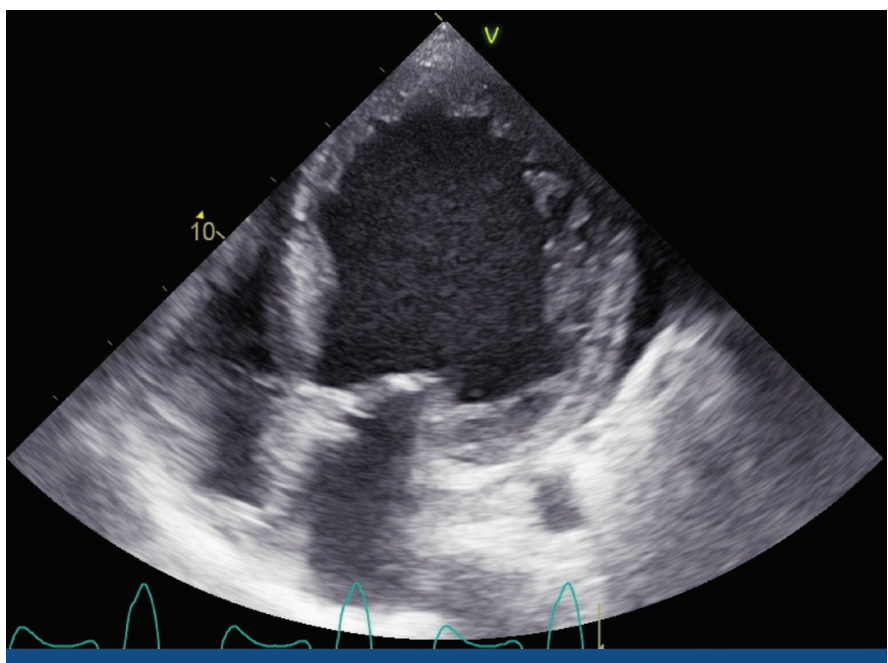

FIGURE 1. Four-chamber view showing ratio of the non-compacted and compacted myocardium.

RECEIVED:

Case report: 75-year-old woman with a prior history of arterial hypertension and atrial fibrillation was hospitalized due to acute heart failure. Physical examination revealed holodiastolic precordial murmur, bilateral pulmonary crackles, and peripheral edema. Echocardiography showed severe regurgitation of tricuspid aortic valve based on the prolapse of the non-coronary cusp and volume overload - induced eccentric left ventricular (LV) hypertrophy with reduced ejection fraction (EF) of 35\%. Moreover, a hypertrabeculation with intertrabecular recesses were observed in the inferolateral and apical region of LV fulfilling the echocardiographic diagnostic criteria for LVNC (Figure 1). Coronary angiography showed no signs of coronary artery disease. The patient was started on standard heart failure therapy and was referred to cardiac surgery for aortic valve replacement (AVR). Postoperative echocardiographic assessment one year after AVR showed no improvement in LV systolic function despite normally functional bioprosthetic aortic valve and standard of care heart failure therapy.

Conclusion: Symptomatic LVNC patients with LV systolic dysfunction generally have poorer prognosis ${ }^{1}$. Since the potential of recovery of myocardial function is questionable in patients with preexisting myocardial disease ${ }^{2}$, the postoperative outcome might not be satisfactory.
July 24, 2021

ACCEPTED:

August 5, 2021

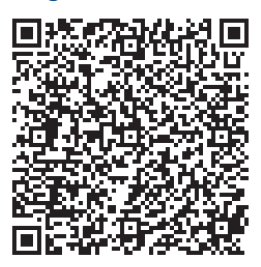

$\square$ Cardiologia Croatica 2021;16(9-10):290.
LITERATURE IIIIIIIIIIIIIIIIIIIIIIIIIIIIIIIIIIIIIIIIIIIIIIIIIIIIIIIIIIIIIIIIIIIIIIIIIIIIIIIIIIIIIIIIIIIII

1. Tanaka H, Kimura T, Miyamoto S. Aortic valve replacement for aortic regurgitation with rare left ventricular non-compaction. Ann Thorac Cardiovasc Surg. 2014;20(1):76-79. https://doi.org/10.5761/atcs.cr.12.01939

2. Banerij A, Tiwari P. Double whammy: Rheumatic heart disease associated with left ventricular noncompaction. J Pract Cardiovasc Sci. 2021; (1):83-4. https://doi.org/10.4103/jpcs.jpcs_82_20 